\title{
PEMBANGUNAN SISTEM INFORMASI PENGOLAHAN DATA PENDUDUK DI KECAMATAN BANJARBARU UTARA
}

\author{
Fakultas Teknologi Informasi \\ Universitas Islam Kalimantan Muhammad Arsyad Al Banjari Banjari Banjarmasin \\ Al Fath Riza Kholdani, S.Kom, M.Kom \\ (kholdanialfath@gmail.com)
}

\begin{abstract}
ABSTRAK
Sistem Informasi pengolahan data penduduk di Kecamatan Banjarbaru Utara membantu menyelesaikan pendataan secara terkomputerisasi pada Data Desa, Data IMB, Data Izin Keramian, Data Izin Usaha, Data Pernikahan, Data Pindah, Data EKTP, Data Kelakuan Baik, Data Domisili, Data Tidak Mampu, Data Keadaan Tanah dan Data Kartu Keluarga. Sinkronisasi data menghasilkan informasi pendataan penduduk pada Kecamatan Banjarbaru Utara secara terorganisir dengan akurat dan cepat. Waktu yang diperlumakan dalam pemrosesan data menjadi lebih singkat dan mempermudah bagi pegawai Kecamatan Banjarbaru Utara dalam menggunakan Sistem Informasi yang interface dirancang secara user friendly. Aplikasi yang berbasis Web menjadikan sistem ini sangat ringkas dalam instalasi dan penggunaan tidak memerlukan sisi hardware dan sofware yang khusus.
\end{abstract}

Kata kunci : Sistem Informasi, Pendataan, Web

Information System of data processing of population in Sub District of North Banjarbaru help complete computerized data collection on Village Data, IMB Data, Permit Permit Data, Data of Business Permit, Wedding Data, Moving Data, E-ID Card, Good Behavior Data, Domicile Data, Data Unable, Land Status Data and Family Card Data. Data synchronization resulted in accurate and fast data collection of population in North Banjarbaru District. The time consumed in data processing becomes shorter and makes it easier for North Banjarbaru Subdistrict employees to use an Information System whose interface is designed in a user friendly manner. Web-based applications make this system very concise in installation and usage does not require a special hardware and software side.

Keywords: Information Systems, Data Collection, Web

\subsection{Pendahuluan}

Kantor Kecamatan Banjarbaru Utara merupakan instansi pemerintahan yang melayani seluruh warga dari 10 Desa. Sistem yang berjalan pada Kantor Kecamatan Banjarbaru Utara saat ini menggunakan aplikasi Microsoft Office dalam pembuatan data surat pengantar, data surat izin, data surat rekomendasi, data surat keterangan, dan lainnya.
Sistem yang berjalan selama ini mempunyai banyak kekurangan antara lain memungkinkan adanya kesalahan dalam pengisisan dan pelaporan, membutuhkan waktu yang lama dalam proses pencarian data, maupun dalam proses pembuatan laporan.

Sumber daya manusia dalam hal pelayanan juga memiliki keterbatasan dalam memahami aplikasi Microsoft 
Office. Ketelitian jadi faktor penting dalam menghasilkan pelayanan yang memuaskan warga. waktu yang diperlukan warga untuk melakukan pengurusan kadang lebih dari satu hari.padahal era teknologi informasi sudah masuk hingga ke Desa-desa.

Berdasarkan kondisi di atas maka peneliti mempunyai inisiatif untuk membuat Sistem Informasi Pengelolaan Data Penduduk Berbasis Web di Kecamatan Banjarbaru Utara. Dengan adanya sistem informasi ini diharapkan akan dapat memudahkan petugas dalam mencari informasi yang dibutuhkan di kantor Kecamatan serta warga pun bisa langsung melakukan tahapan untuk pendataan secara online.

\subsection{Rumusan Masalah}

Berdasarkan uraian di atas, maka permasalahan yang timbul adalah:

1. Bagaimana membuat sistem informasi yang dapat dengan mudah digunakan pegawai dan warga?

2. Bagaimana sistem informasi dapat digunakan untuk pengolahan dan pelaporan data warga?

\subsection{Batasan Masalah}

Penelitian ini memiliki batasan masalah, yaitu :

1. Penelitian dilakukan hanya pada Kecamatan Banjarbaru Utara.

2. User dibagi menjadi 2 macam, yaitu Petugas dan Warga. Petugas mempunyai hak untuk menambah, mengubah dan menghapus data, sedangkan Warga hanya bisa melihat informasi yang disediakan.

3. Pembuatan Sistem Menggunakan Bahasa Pemrograman PHP, Javascript \& Database MySQL.

\subsection{Tujuan}

Tujuan dari penulisan laporan ini adalah membangun aplikasi kependudukan yang diharapkan mampu untuk:

1. Dengan adanya sistem informasi pengolahan data penduduk yang terkomputerisasi ini dapat membantu kinerja petugas menjadi lebih mudah dan efisien.

2. Sistem yang dibuat dapat melakukan pencarian data-data surat, yaitu surat pengantar, surat izin, surat rekomendasi, dan surat keterangan.

\subsection{Manfaat}

Adapun manfaat dari penulisan laporan ini adalah sebagai berikut :

1. Memberikan kemudahan bagi petugas dalam melakukan pengelolaan data penduduk dan pelayanan kepada masyarakat di Kecamatan Banjarbaru Utara.

2. Mempercepat dalam proses pembuatan dan pendataan surat keterangan, surat izin, surat pengantar, dan surat rekomendasi.

3. Mempercepat dan mempermudah dalam proses pencarian data.

4. Memudahkan warga dalam mendapatkan berita yang dikeluarkan oleh Kecamatan.

\subsection{Landasan Teori}

\section{A. Sistem}

Sistem adalah kumpulan dasri sistem atau bagian atau komponen apapun baik pisik maupun non pisik yang saling berhubungan satu sama lain dan bekerja sama secara harmonis untuk dapat mencapai suatu tujuan tertentu. (Winarno, 2006).

Sistem adalah rangkaian dari dua atau lebih komponen-komponen yang saling berhubungan, yang berinteraksi untik mencapai suatu tujuan. (romney \& steinbart, 2006).

\section{B. Sistem Informasi \\ Sistem Informasi adalah sebuah prosedur normal dimana data}


dikelompokkan, diproses menjadi informasi, dan didistribusikan kepada pemakai. (Laudon \& Laudon, 2008).

Sistem informasi adalah suatu sistem buatan manusia yang secara umum terdiri atas sekumpulan komponen berbasis komputer dan manual yang dibuat untuk menghimpun, menyimpan, dan mengelola data serta menyediakan informasi keluaran kepada pemakai. (Sutabri, 2010).

Menurut (Kusrini \& Koniyo, 2007) Siklus hidup pengembangan sistem (system life cyle) menggambarkan tahapan-tahapan utama dan langkahlangkah dari setiap tahapan :

1. Problem definition.

2. Feasibility study, bertujuan untuk mengetahui ruang lingkup pekerjaan.

3. Analysis, bertujuan untuk memahami system yang ada, mengidentifikasi masalah dan mencari solusi.

4. System design, bertujuan untuk mendesain system baru yang dapat menyelesaikan masalah-masalah yang dihadapi perusahaan.

5. Detailed design, membuat sistem baru (hardware dan software).

6. Implementation, bertujuan untuk mengimplementasikan siste yang baru.

7. Maintance, bertujuan agar system dapat berjalan secara optimal

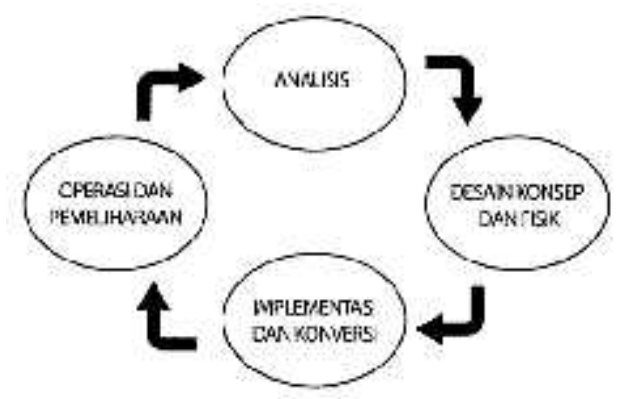

Gambar 2. 1 Siklus Perkembangan Sistem Informasi

\section{Data Flow Diagram}

Teknis grafis dalam menggambarkan aliran informasi disebut sebagai Data Flow Diagram yang memiliki berbagai macam simbol-simbol yang kemudian diaplikasikan pada suatu sistem informasi dari input menjadi output. DFD memberikan suatu mekanisme bagi pemodelan fungsional dan pemodelan aliran informasi. Model ini menggambarkan sistem sebagai jaringan kerja antar fungsi yang berhubungan satu sama lain dengan aliran penyimpanan data. Data Flow Diagram merupakan alat bantu dalam membuat perancangan suatu aplikasi, model ini mampu menjelaskan sistem dari sudut pandang fungsi diagram alir. (HM, 2005)

Tempat komponen utama dalam pemodelan ini, antara lain:

1. Proses

Komponen pertama dalam model ini dinamakan proses. Proses menunjukkan transformasi dari masukan menjadi keluaran. Dalam hal ini sejumlah masukan dapat menjadi hanya satu keluaran ataupun sebaliknya.

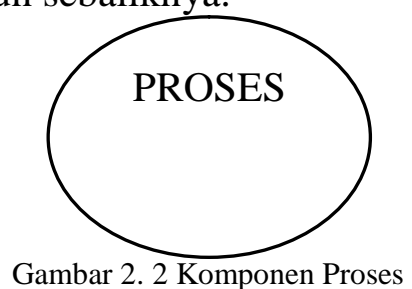

2. Aliran

Komponen yang digunakan dalam membuat aliran yaitu arah panah yang menuju ke atau dari proses. Digunakan untuk menggambarkan gerakan paket data atau informasi dari satu bagian ke bagian lain dari sistem dimana penyimpanan mewakili lokasi penyimpanan data. 
Gambar 2. 3 Komponen Aliran

3. Penyimpanan

Komponen ini digunakan untuk memodelkan kumpulan data atau paket data. Notasi yang digunakan adalah garis sejajar, segiempat dengan sudut melengkung ataupun persegi panjang.

Gambar 2. 4 Komponen Penyimpanan

4. Terminator

Komponen ini digunakan dalam bentuk persegi panjang yang mewakili entity luar dimana sistem berkomunikasi. Biasanya notasi ini melambangkan orang atau sekelompok orang misalnya organisasi, grup, departemen dan entity lain yang berada di luar sistem.

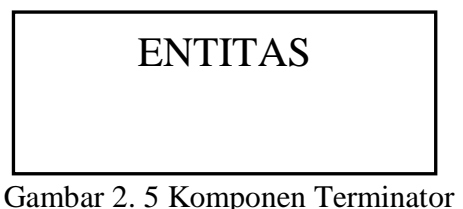

\section{PHP}

Menurut (Paranginangin, 2006) PHP merupakan bahasa pemrograman yang populer dalam pembuatan berbasis website baik dinamis maupun statis. Kepanjangan PHP adalah Hypertext Preprocessor merupakan suatu bahasa pemrograman. PHP manunggal dengan kode HTML, maksudnya adalah sama tetapi beda kondisi. Bahasa pemrograman dengan HTML diimplementasikan sebagai pembangun atau pondasi dari kerangka layout web, sedangkan PHP difungsikan sebagai prosesnya sistemnya sehingga dengan adanya kolaborasi tersebut, web akan sangat mudah di kelola. PHP dijalankan pada sisi server komputasi sehingga PHP disebut juga sebagai bahasa Server Side Scripting, Artinya bahwa saat PHP dijalankan wajib adanya sebuah web server.

Bahasa pemrograman PHP bersifat terbuka dan bebas sehingga dapat dipakai secara cuma-cuma dan mampu lintas platform, yaitu dapat berjalan pada sistem operasi Windows maupun Linux. PHP dapat juga dijadikan sebagai modul pada web server apache dan sebagai binary yang dapat berjalan sebagai CGI dalam pembangunannya.

Ada beberapa kelebihan yang menjadi dasar perhitungan mengapa menggunakan PHP, berikut alasannya:

1. Mudah dipelajari, alasan tersebut menjadi salah satu alasan utama untuk menggunakan PHP, Pemula pun akan mampu untuk menjadi web master PHP. 9

2. Dapat diaplikasikan pada berbagai Lintas Platform, artinya PHP dapat / mudah digunakan ke berbagai platform OS (Operating Sytem) dan hampir semua browser juga mendukung bahasa pemrograman PHP.

3. Free alias Gratis, bersifat Open Source.

4. PHP memiliki tingkat akses yang cepat.

5. Didukung oleh beberapa macam web server, PHP mendukung beberapa web server, seperti Apache, IIS, Lighttpd, Xitami. Bahasa pemrograman PHP sangat mendukung beberapa aplikasi basis data, baik yang gratis maupun yang berbayar, seperti aplikasi basis data berikut MySQL, PostgreSQL, mSQL, Informnix, SQL server, Oracle.

\section{E. Java Script}

Menurut (Yeni Kustiyahningsih dan Devie Rosa Anamisa, 2011 ) JavaScript adalah bahasa yang berbentuk kumpulan skrip berjalan pada suatu dokumen 
HTML. Bahasa pemrograman JavaScript adalah salah satu bahasa pemrograman komputer yang sangat mampu memberikan kemampuan lebih terhadap bahasa HTML dengan diizinkannya pengeksekusian perintah-perintah yang disisi user hal ini berarti pada sisi browser bukan pada server web.

JavaScript adalah bahasa yang membedakan penamaan variabel dan fungsi yang menggunakan huruf besar dan huruf kecil atau biasa disebut case sensitive. Beberapa contoh variabel atau fungsi dengan nama berbeda dengan variabel dengan nama test dan setiap instruksi diakhiri dengan karakter titik koma(;). (Abdin, 2016)

\section{F. Mysql}

Menurut (Andrea Adelheid, 2011)

Basis data adalah sekumpulan informasi yang diatur agar mudah dicari. basis data dalam pengertian secara umum adalah sekumpulan data-data yang diproses degan bantuan teknologi komputer yang memungkinkan data dapat diakses dengan cepat, mudah dan tepat dan dapat digambarkan sebagai aktivitas dari satu atau lebih organisasi yang berelasi. MySQL merupakan suatu pendukung untuk basis data. MySQL dapat juga dikatakan sebagai databaseyang sangat cocok bila dipadukan dengan PHP. Secara umum, database berfungsi sebagai tempat atau wadah untuk menyimpan, mengklasifikasikan data secara prefosional. MySQL bekerja menggunakan SQL Language (Structure Query Language) dalam pengelolaan data. Itu dapat diartikan bahwa MySQL merupakan standar penggunaan basis data di dunia untuk pengolahan dan pengelolaan data. Basis data MySQL termasuk dalam jenis RDBMS (Relational Database Management System) yang open source. RDBMS dalam basis data lebih banyak dikenal dengan istilah-istilah macam tabel, baris, dan kolom digunakan dalam perintahperintah di MySQL. MySQL merupakan sebuah basis data yang mengandung satu atau sejumlah tabel. Tabel data MySQL terdiri dari beberapa baris, dan setiap baris mengandung satu atau lebih beberapa kolom. Di dalam PHP telah menyediakan fungsi untuk koneksi ke basis data dengan sejumlah fungsi untuk pengaturan baik menghubungkan maupun memutuskan koneksi dengan server database MySQL sebagai sarana untuk mengumpulkan informasi.

Pada umumnya, perintah yang paling sering digunakan dalam mySQL adalah select (mengambil), insert (menambah), update (mengubah), dan delete (menghapus). Selain dari itu, MySQL juga disediakan beberapa perintah untuk membuat database, field, ataupun index guna menambah atau menghapus data.

\subsection{Analisis Sistem}

Analisis Kebutuhan merupakan tahap pengumpulan data-data yang diperlukan untuk digunakan sebagai dasar pegembangan sistem informasi. Anlasisis kebutuhan yang digunakan berupa : studi lapangan (observasi), pengumpulan sumber-sumber materi (studi pustaka) dan pencarian penelitian yang relevan. Adapun usulan sistem yang berkembang adalah sebagai berikut:

1. Sistem mampu melakukan pendataan pegawai kantor kecamatan.

2. Sistem mampu membuat surat yang dikeluarkan oleh kantor kecamatan.

3. Sistem mampu menyimpan data surat yang dikeluarkan oleh desa.

4. Sistem mampu melakukan pencarian data surat.

5. Sistem mampu membuat berita mengenai kecamatan. 
6. Sistem mampu mendata desa yang ada di kecamatan.

\subsection{Perancangan Model}

Diagram konteks adalah alur diagram yang terdiri dari suatu atau beberapa proses untuk digambarkan ke ruang lingkup suatu sistem. Diagram konteks merupakan level tertinggi dari DFD yang menggambarkan seluruh input ke sistem atau output dari sistem.

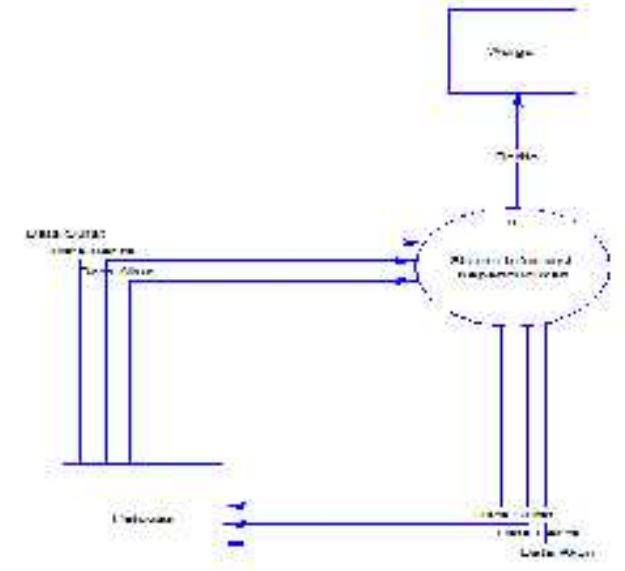

Gambar 3.1 Diagram Konteks
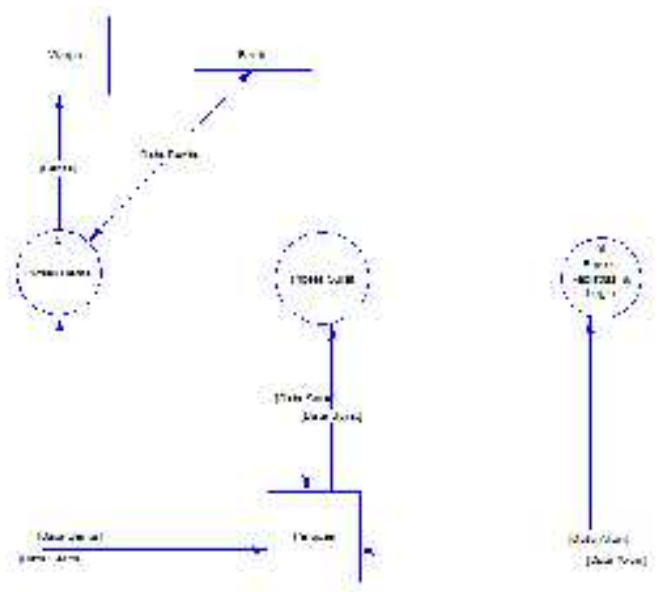

Gambar 3.2 DFD Level 1

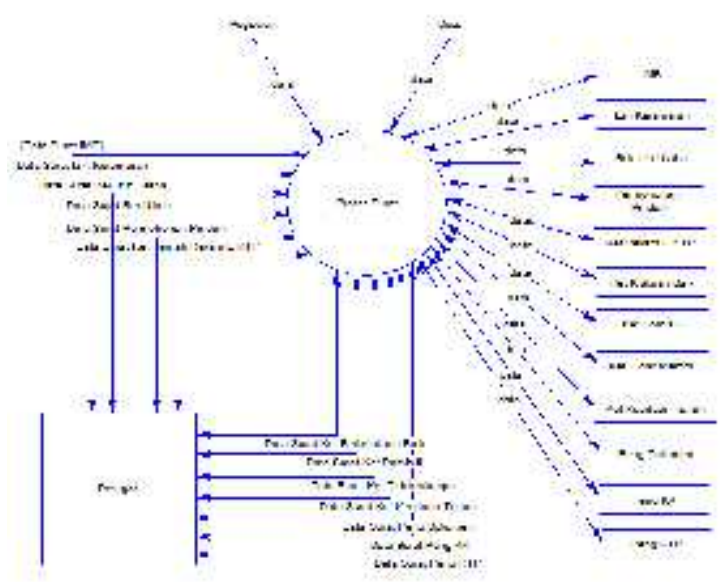

Gambar 3.3 DFD Level Proses Surat

\subsection{Perancangan Database}

Aplikasi yang dibangun memilki basis data yang terdiri dari tujuh belas tabel. Tabel tersebut berelasi agar sistem dapat berjalan sempurna, berikut Gambar tampilan relasi antar tabel tersebut:

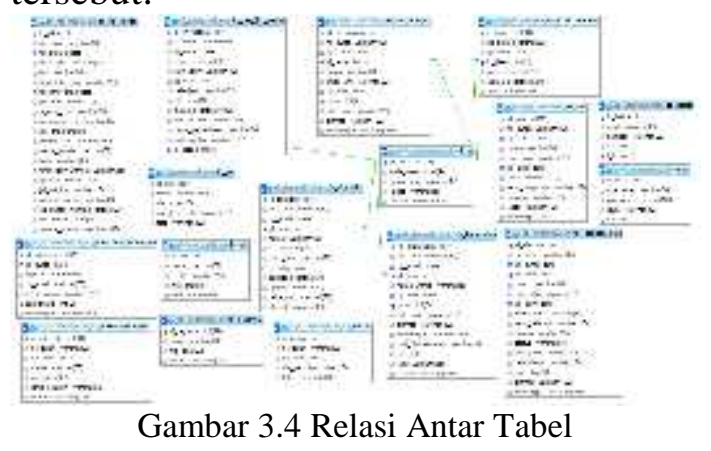

\subsection{Implementasi Sistem}

\section{A. Halaman Login}

Halaman ini digunakan untuk login kedalam program. Halaman ini merupakan pengamanan agar tidak semua orang bisa masuk menu utama dengan mengisi Username dan Password. prosesnya jika Username dan/atau Password tidak benar maka proses tidak akan berhasil dan menu utama tidak akan terbuka. 


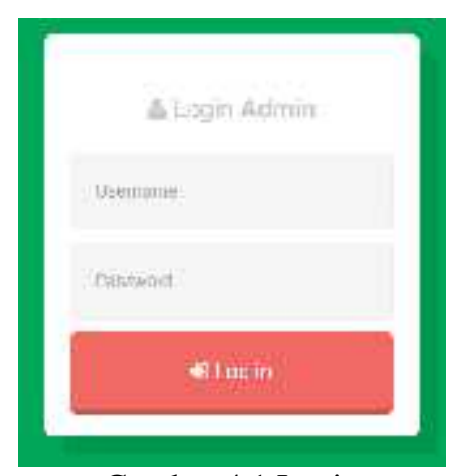

Gambar 4.1 Login

\section{B. Halaman Data Pegawai}

Halaman ini merupakan tampilan dari data pegawai yang berisi tambah data, no, nama, nip, jabatan, dan dua action berupa edit dan hapus data.

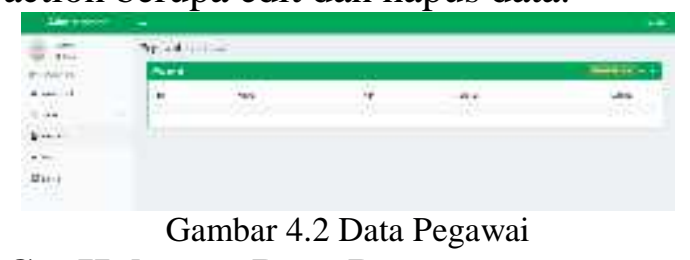

\section{Halaman Data Desa}

Halaman ini merupakan tampilan dari data desa yang berisi tambah data, no, kode desa, nama desa, kepala desa, alamat dan dua action yaitu edit dan hapus.

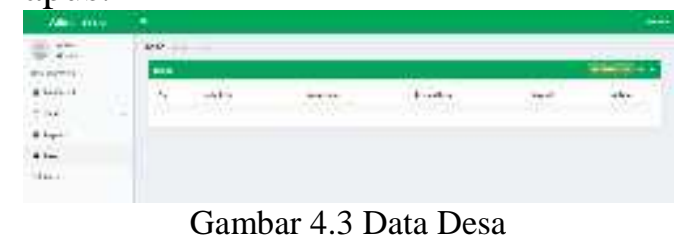

\section{Halaman Data Berita}

Halaman ini merupakan tampilan dari data berita yang berisi tambah data, no, judul berita, foto, isi berita, tanggal input, dan dua aksi yaitu edit dan hapus. Button edit digunakan untuk mengedit Data sedangkan button hapus digunakan untuk mengahpus data.

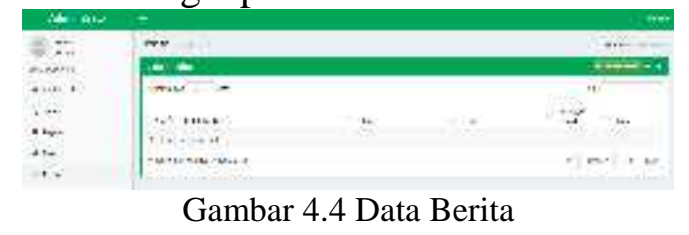

\section{E. Halaman IMB}

Halaman ini merupakan tampilan dari data surat IMB yang berisi field no, no surat, tanggal surat, nama, tempat/tgl lahir, jenis bangunan, panjang, lebar, action, dan 4 button yaitu detail, edit, delete, dan cetak. Button detail digunakan untuk melihat detail data surat IMB, button edit digunakan untuk mengedit data, button delete untuk menghapus data, dan button cetak digunakan untuk mencetak surat IMB.

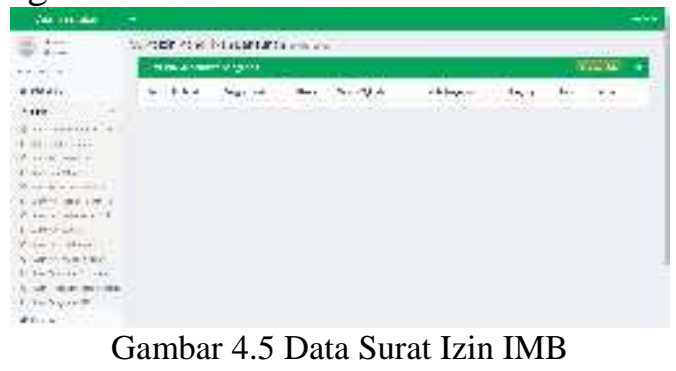

\section{F. Halaman Izin Keramaian}

Halaman ini merupakan tampilan dari data surat keramaian yang berisi field no, no surat, tanggal surat, nama warga, hari pelaksanaan, tanggal, jam, action, dan 4 button yaitu detail, edit, delete, dan cetak. Button detail digunakan untuk melihat detail data surat izin keramaian, button edit digunakan untuk mengedit data, button delete untuk menghapus data, dan button cetak digunakan untuk mencetak surat izin keramaian.

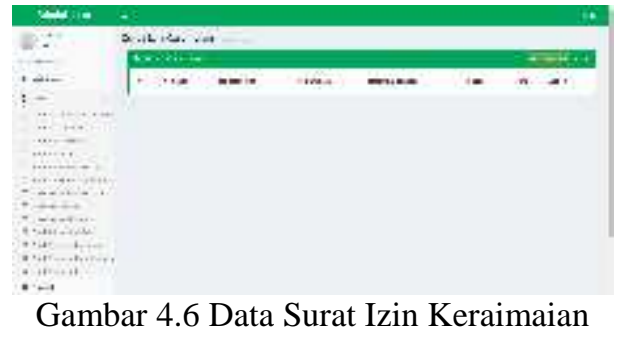

\section{G. Halaman Rek Izin Usaha}

Halaman ini merupakan tampilan dari data surat rekomendasi izin usaha yang berisi field no, no surat, tanggal surat, nama, nik, tempat/tanggal lahir, pekerjaan, action, dan 4 button yaitu 
detail, edit, delete, dan cetak. Button detail digunakan untuk melihat detail data surat rekomendasi izin usaha, button edit digunakan untuk mengedit data, button delete untuk menghapus data, dan button cetak digunakan untuk mencetak surat rekomendasi izin usaha.

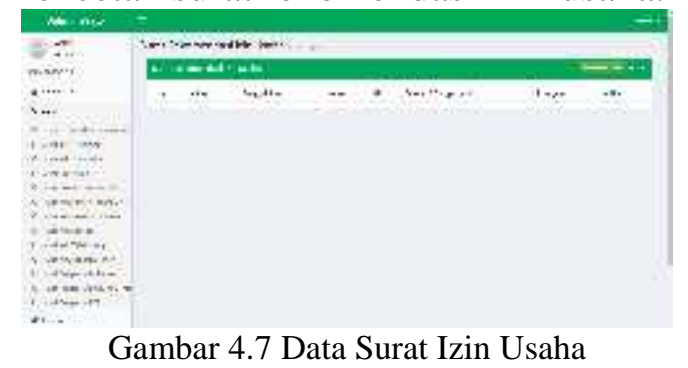

\section{H. Halaman Rek Menikah}

Halaman ini merupakan tampilan dari data surat rekomendasi nikah yang berisi field no, no surat, tanggal surat, nik laki-laki, nama laki-laki, nik perempuan, nama perempuan, action, dan 4 button yaitu detail, edit, delete, dan cetak. Button detail digunakan untuk melihat detail data surat rekomendasi nikah, button edit digunakan untuk mengedit data, button delete untuk menghapus data, dan button cetak digunakan untuk mencetak surat rekomendasi nikah.

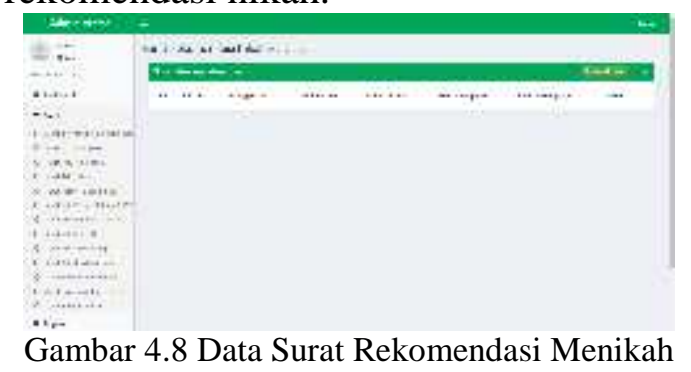

\section{Halaman Pindah}

Halaman ini merupakan tampilan dari data surat permohonan pindah yang berisi field no, no surat, tanggal surat, nik pemohon, foto, action, dan 4 button yaitu edit, delete, cetak, dan download. Button edit digunakan untuk mengedit data, button delete untuk menghapus data, button cetak digunakan untuk mencetak surat permohonan pindah, dan button download digunakan untuk mendownload foto.

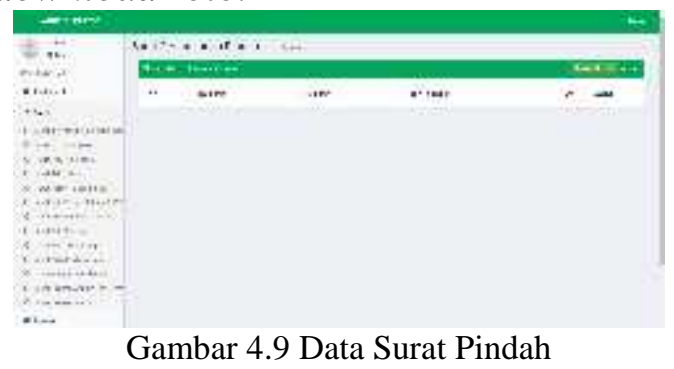

\section{J. Halaman Pernah Rekam EKTP}

Halaman ini merupakan tampilan dari data surat keterangan pernah rekam e-ktp yang berisi field no, no surat, tanggal surat, nama, nik, jenis kelamin, alamat, action, dan 4 button yaitu detail, edit, delete, dan cetak. Button detail digunakan untuk melihat detail data surat keterangan pernah rekam e-ktp, button edit digunakan untuk mengedit data, button delete untuk menghapus data, dan button cetak digunakan untuk mencetak surat keterangan pernah rekam e-ktp.

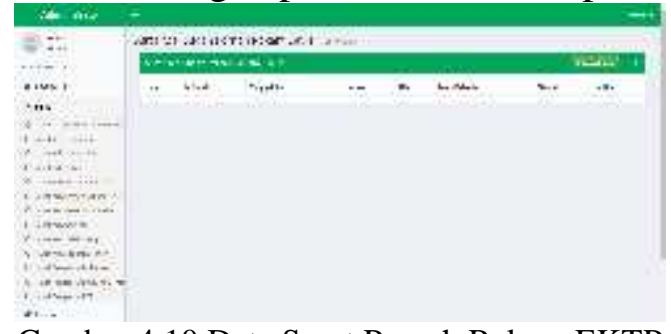

Gambar 4.10 Data Surat Pernah Rekam EKTP

\section{K. Halaman Kelauan Baik}

Halaman ini merupakan tampilan dari data surat keterangan berkelakuan baik yang berisi field no, no surat, tanggal surat, nama, nik, jenis kelamin, agama, status, action, dan 4 button yaitu detail, edit, delete, dan cetak. Button detail digunakan untuk melihat detail data surat keterangan berkelakuan baik, button edit digunakan untuk mengedit data, button delete untuk menghapus data, dan button cetak digunakan untuk mencetak surat keterangan berkelakuan baik. 


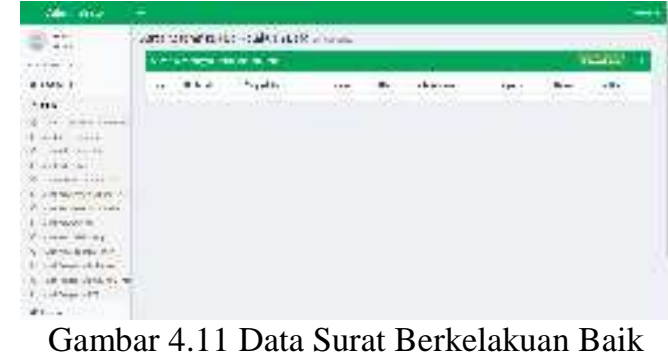

\section{Halaman Keterangan Domisili}

Halaman ini merupakan tampilan dari data surat keterangan domisili yang berisi field no, no surat, nama warga, jenis kelamin, kebangsaan, agama, action, dan 4 button yaitu detail, edit, delete, dan cetak. Button detail digunakan untuk melihat detail data surat keterangan domisili, button edit digunakan untuk mengedit data, button delete untuk menghapus data, dan button cetak digunakan untuk mencetak surat keterangan domisili.

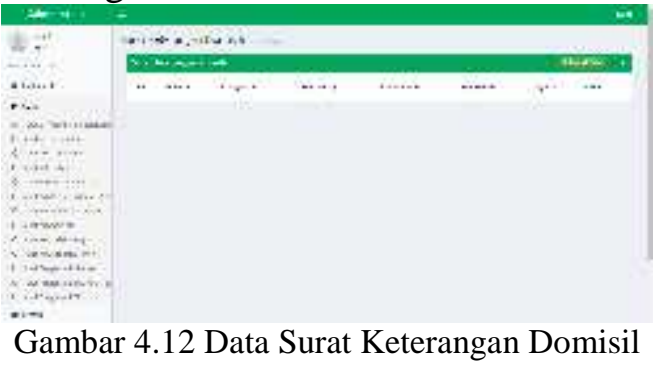

\section{Halaman Ket Tidak Mampu}

Halaman ini merupakan tampilan dari data surat keterangan tidak mampu yang berisi field no, no surat, tgl surat, nama warga, pekerjaan, action, dan 4 button yaitu detail, edit, delete, dan cetak. Button detail digunakan untuk melihat detail data surat keterangan tidak mampu, button edit digunakan untuk mengedit data, button delete untuk menghapus data, dan button cetak digunakan untuk mencetak surat keterangan tidak mampu.

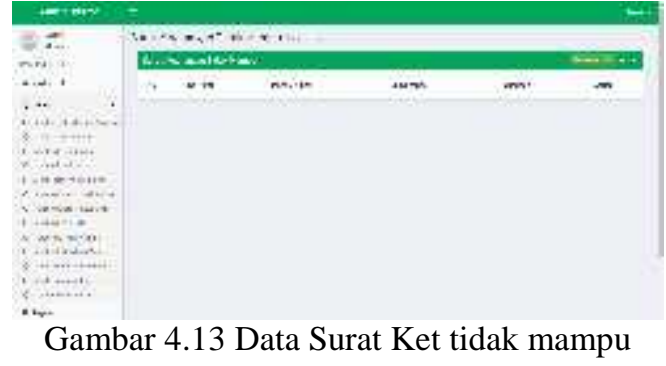

\section{N. Halaman Keadaan Tanah}

Halaman ini merupakan tampilan dari data surat keterangan keadan tanah yang berisi field no, no surat, tgl surat, nama, alamat, foto, action, dan 4 button yaitu edit, delete, cetak, dan download. Button edit digunakan untuk mengedit data, button delete untuk menghapus data, button cetak digunakan untuk mencetak surat keterangan keadaan tanah, dan button download digunakan untuk men-download foto surat keadaan tanah.

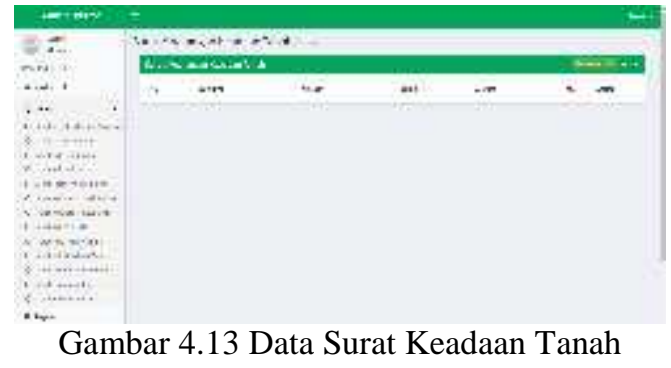

\section{O. Halaman Pengantar Dokumen}

Halaman ini merupakan tampilan dari data surat pengantar dokumen yang berisi field no, no surat, tgl surat, kepada, jenis kirim, banyaknya, keterangan, action, dan 3 button yaitu edit, delete, dan cetak. Button edit digunakan untuk mengedit data, button delete untuk menghapus data, dan button cetak digunakan untuk mencetak surat pengantar dokumen.

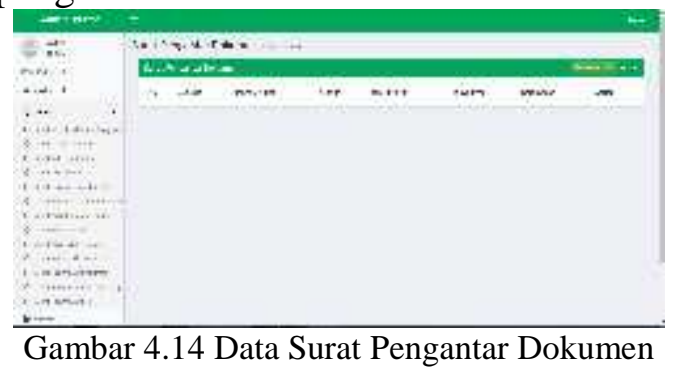




\section{P. Halaman Kartu Keluarga}

Halaman ini merupakan tampilan dari data surat pengantar kartu keluarga yang berisi field no, nama pemohon, nik pemohon, no kk semula, foto, action, dan 4 button yaitu edit, delete, cetak, dan download. Button edit digunakan untuk mengedit data, button delete untuk menghapus data, button cetak digunakan untuk mencetak surat pengantar kartu keluarga, dan button download digunakan untuk men-download foto surat pengantar kartu keluarga.

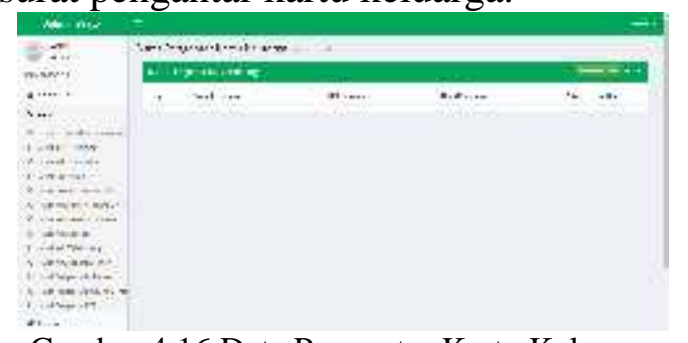

\section{Q. Halaman Pengantar KTP}

Halaman ini merupakan tampilan dari data surat pengantar ktp yang berisi field no, nama pemohon, no kk, nik, foto, action, dan 4 button yaitu edit, delete, cetak, dan download. Button edit digunakan untuk mengedit data, button delete untuk menghapus data, button cetak digunakan untuk mencetak surat pengantar ktp, dan button download digunakan untuk men-download foto surat pengantar KTP.

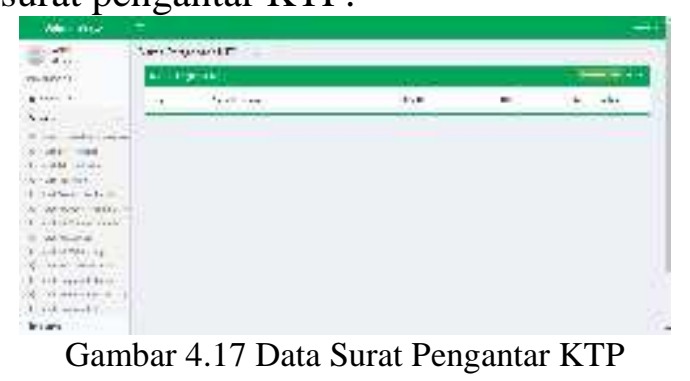

\subsection{Kesimpulan}

Setelah melalui tahap
perencanaan, pembuatan dan
serangkaian pengujian terhadap
perangkat lunak dalam pembangunan
sistem informasi pengolahan data

penduduk di Kecamatan Banjarbaru Utara, dapat disimpulkan beberapa hal sebagai berikut :

1. Sistem informasi pengolahan kependudukan yang dibangun dapat memudahkan proses pengolahan data surat izin, surat keterangan, surat rekomendasi, surat pengantar, dan surat permohonan.

2. Aplikasi ini dapat menghemat waktu dan meningkatkan kinerja dalam mengolah data surat serta dapat melakukan pencarian data yang diinginkan dengan cepat.

3. Sistem baru diharapkan dapat memperkecil kesalahan pegawai dalam penyimpanan data atau dokumen penduduk.

4. Tampilan aplikasi ini di rancang dengan konsep Interface User Friendly, yang di maksudkan agar memudahkan penggunaan aplikasi.

\subsection{Saran}

Sistem informasi kependudukan di Kecamatan Banjarbaru Utara dapat dikembangkan menjadi sistem informasi terdistribusi antara kecamatan dan desa serta dapat terpusat pada Kota atau Kabupaten. Selanjutnya dapat dimulai dari sistem informasi yang mampu menjembatani pengolahan data kependudukan dari tingkat desa ke tingkat kecamatan terus hingga ke Pusat melalui pengembangan multi-platform.

\section{DAFTAR PUSTAKA}

Abdin, A. (2016, Mei 22). Pengertian Http Dan Javascript Menurut Ahli. Retrieved from http://www.membacaartikel.tk

Andrea Adelheid, K. N. (2011). Buku Pintar Menguasai PHP dan MySQL. Jakarta Selatan: Media Kita.

Arisanti, A. (2013). Perancangan Sistem Informasi Pendataan Penduduk Berbasis Web Menggunakan 


\author{
Metode Waterfall pada Desa \\ Bogorejo Kecamatan \\ Gedongtataan.
}

HM, J. (2005). Analisis \& Desain Sistem

Informasi . Jakarta: Eirlangga

Publisher.

Kusrini, \& Koniyo, A. (2007). Tuntunan

Praktis Membangun Sistem

Informasi Akuntansi dengan

Visual Basic dan Microsoft SQL

Server. Yogyakarta: Penerbit

Andi.

Laudon, K. C., \& Laudon, J. P. (2008).

Sistem Informasi Manajemen:

Mengelola Perusahaan Digital 2

Edisi 10. Jakarta: Salemba

Empat.

Paranginangin, K. (2006). Aplikasi web dengan PHP dan My SQL. Jakarta: Andi.

Priyanti, D. (2013). Sistem Informasi Data Penduduk Pada Desa Bogoharjo Kecamatan Ngadirojo Kabupaten Pacitan.

Romney, \& steinbart, p. j. (2006). Sistem Informasi Akuntansi. Jakarta: Salemba Diniyah.

Setiawan, D., \& Mahendra, Y. A. (2015). Perancangan Sistem Informasi Penduduk Pada Kantor Desa Kebonsari.

Soeherman, B., \& Pinontoan, M. (2008). Designing Information System. Jakarta: Elex Media Komputindo.

Supriyanto, W., \& Muhsinin, A. (2008). Teknologi Informasi perpustakaan. Yogyakarta: Penerbit Kanisius.

Sutabri, T. (2010). Sistem Informasi Manajemen . Jakarta: Andi Publisher.

Winarno, W. W. (2006). Sistem Informasi Akuntansi. Yogyakarta: UPP STIM YKPN. 